Espacio, Tiempo y Forma, Serie IV, Historia Moderna, t. 17, 2004, págs. 59-75

\title{
Pedro Páez y la misión jesuítica en Etiopía en el contexto de la unión de las Coronas de España y Portugal*
}

\author{
marina Alfonso Mola y Carlos Martínez Shaw \\ UNED (Madrid)
}

\section{RESUMEN ABSTRACT}

Pedro Páez fue el religioso español que encabezó la segunda misión jesuítica en Etiopia, iniciada en 1603. Pese a su éxito en la adhesión al catolicismo del emperador Susenios, su labor se vio condicionada por su desarrollo en un área de influencia portuguesa y en un momento de rivalidad entre las diversas órdenes que actuaban en los territorios ultramarinos situados respectivamente bajo el dominio de España y Portugal.
Pedro Páez was the Spanish priest who led the second Jesuit mission in Ethiopia, from 1603 on. Although his success in submitting Emperor Susenyos to the Catholic Church, his task was conditioned by its development in a area under Portuguese influence and in a period of rivalry between diverse religious orders that acted in the overseas territories put under the dominion of Spain and Portugal.

Cuando en 1581 ias Cortes reunidas en Tomar dan su consentimiento a la "agregación» de la Corona de Portugal a la Monarquia Hispánica, Felipe II se convierte en «rey de España, primero de su nombre en Portugal», reconstruyendo de ese modo la antigua unidad de la Hispania romana bajo un único soberano. Ahora bien, los pactos que llevan a la aceptación de tal estado de cosas por los estamentos lusitanos establecen claramente que Portugal ha de conservar su constitución privativa dentro de la monarquía compuesta hispana, del mismo modo que los restantes territorios (reinos, ducados, señoríos, etc.) incluidos bajo la soberanía del Rey Prudente. Y esto, además, era válido para todos los estados portugueses de Ultramar, ya se tratase de las plazas africanas, del Estado do Brasil o del Estado da Índia.

* La versión definitiva de este artículo debe mucho a los debales del Seminario sobre Pedro Páez in Early Seventeenth Century Ethiopia (Addis Ababa, 2003), y especialmente a las contribuciones de los profesores Isabel Boavida, Hervé Pennec y Manuel João Ramos. 
Esto significaba que los portugueses seguirian siendo extranjeros en las tierras de Castilla y los castellanos seguirian siendo extranjeros en las tierras de Portugal'.

Esta era la teoría constitucional establecida, pero la realidad fue siempre más compleja. En primer lugar, si bien no llegó a implantarse una auténtica Unión de Armas en Oriente, de acuerdo con los deseos que manifestaría el Conde Duque de Olivares a partir de 1622 en tiempos de Felipe IV, también es cierto que fueron en gran parte las tropas castellanas bajo el mando directo de los gobernadores de Filipinas las que en muchas ocasiones hubieron de hacerse cargo de la defensa de los intereses portugueses en Asia, especialmente frente a la amenaza holandesa 2 . Apenas si hace falta recordar al respecto las intervenciones en defensa de las Molucas, que terminaron en 1606 con la expulsión de los holandeses a cargo de una flota de 33 barcos y una tropa de tres mil hombres financiadas desde México y con la instalación de guarniciones españolas en sendas fortalezas en las islas de Tidore y Ternate. Ni tampoco la defensa de Macao en ocasión del ataque holandés de 1622, a la que contribuyeron las autoridades filipinas con el envío de dos compañías de soldados y doce piezas de artillería. Ni tampoco, por último, la asunción por parte de España de la protección de Formosa, estableciendo una guarnición en 1626 y manteniendo los presidios de Jilong y Tamsui en el norte de la isla desde 1628 hasta agosto de $1641^{3}$.

Con este telón de fondo se entiende la propuesta del gobernador español Juan Niño de Távora, poco antes de su muerte, en 1632, de aunar la jurisdicción de Manila con la de Macao: «El juntar estas plazas debajo de una mano no ha de ser dificultoso, aunque sean de dos coronas, que si ellas en sí no se unen, no tendrán fuerzas. Portugal y Castilla de Vuestra Majestad son, y así es razón que sus Armas anden unidas, pues las de Francia, Holanda, Inglaterra y Dinamarca lo andan en estas partes; y si lo anduviesen las de Vuestra Majestad, no sólo defenderíamos lo ganado, sino que pasáramos cada dia más adelante. A ellos les ve Vuestra Majestad unidos entre sí, siendo de tan diferentes señores, naciones, religión y naturales;

Sobre los aspectos constitucionales de la "agregación» de Portugal, cf. F. J. Bouza Álvarez: Portugal en la Monarquia Hispánica. Felipe II, las Cortes de Tomar y la génesis del Portugal Católico, Madrid, 1987 (tesis doctoral inédita). Del mismo autor, resulta también interesante: Portugal no tempo dos Filipes (1580-1668), Lisboa, 2000. Por último, cf. J. F. Schaub: Le Portugal au temps du Comte Duc d'Olivares (1621-1640). Le conflit de jurisdictions comme exercice de la politique, Madrid, 2001.

2 Sobre la Unión de Armas en Filipinas, cf. R. Valladares: Castilla y Portugal en Asia (1580-1680). Declive imperial y adaptación, Lovaina, 2001, pp. 37-64; y del mismo autor: "Olivares y Oriente. La Unión de Armas en Asia, 1622-1642", en M. D. Elizalde, J. M. Fradera y L. Alonso (eds.): Imperios y naciones en el Pacífico, Madrid, 2001, t. I, pp. 73-80.

${ }^{3}$ Cf. C. Martinez Shaw: "The overseas Spanish Empire and the Dutch Republic before and after the Peace of Munster», en De zeventiende eeuw, n..$^{\circ}$, 1 (1997), pp. 131-138. (Reeditada en 1648. De Vrede van Munster, Hilversum, 1997, pp. 131-138. Traducida al castellano: “El Imperio colonial español y la República holandesa tras la paz de Münster», Pedralbes, n. ${ }^{\circ} 19$ (1999), pp. 117-129. Y reeditada, finalmente en H. de Schepper (ed.): La paz de Münster, Barcelona, 2000, pp. 75-86). Cf. asimismo, M. Alfonso Mola y C. Martinez Shaw: “La defensa del Imperio de Ultramar», en M. Alfonso Mola y C. Martínez Shaw (eds.): Esplendores de España. Del Greco a Velázquez, Río de Janeiro, 2000, pp. 80-89 (Traducida al portugués: "A defesa do Império Ultramarino", en M. Alfonso Mola y C. Martínez Shaw (eds.): Esplendores de Espantia. De El Greco a Velázquez, Rio de Janeiro, 2000, pp. 80-89). 
pues, ¿por qué no se unirian Portugal y Castilla en este Mar del Sur y costas del Asia, de donde tanta riqueza lleva el enemigo? ${ }^{4}$. Era esta una idea con la que estaban de acuerdo incluso algunos mandatarios portugueses, como el almirante Diogo Lopes Lobo, que en carta al gobernador de Manila había argumentado años antes sobre la conveniencia de que se uniesen «las plazas de Malaca y Macao con las de Manila y Maluco y se pongan debajo de una misma mano, de manera que anden las armas unidas y se haga un cuerpo de fuerza cuyo distrito sea el Mar del Sur hasta el estrecho de Malaca, y que no será razón que por puntos que los portugueses pudieran tener en esto dejase Su Majestad de ajustar su Monarquía en las partes que ella le conviene, pues de lo contrario será crecer cada día más el poder del enemigo" ${ }^{5}$. La unión, al decir del sucesor de Niño de Távora, el gobernador Sebastián Hurtado de Corcuera, hubiera producido notables beneficios para la salvaguarda de los intereses estratégicos y económicos de españoles y portugueses en la región: "Si se hubiera hecho esto antes quizá no se hubiera perdido la ciudad de Malaca, y estas Islas Filipinas, por vía de la ciudad de Macán, hubiera conseguido más conveniencias y comodidades en el trato y comercio necesario" ${ }^{6}$.

Algo parecido puede decirse en el terreno de la vida comercial. Sin duda la línea de puestos mercantiles portugueses (en resumen, Goa, Colombo, Malaca, Molucas, Macao, Nagasaki) siguió vedada a los mercaderes hispanos, pero, por el contrario, los barcos lusitanos desempeñaron un activo papel en el tráfico desarrollado en los vértices del triángulo China-Japón-Filipinas, llevando sedas chinas a Nagasaki y Manila, y trayendo a cambio plata japonesa y plata americana para aliviar la sed de metal blanco de la China de los Ming. De ese modo, el gran "barco de Amacón» o la "nau da prata" se convirtió durante los años de vigencia de la unión de las coronas en el principal elemento de confluencia económica del Pacífico de los Ibéricos?.

Tampoco la política dejó de explorar las posibilidades abiertas por la nueva situación. Si Felipe II podía proclamar que «en sus dominios no se ponía nunca el sol", la tentación de incluir la historia de la expansión portuguesa dentro de la historia general hispana se reveló incontenible. Es el caso del padre Juan de Mariana, que a la hora de escribir su Historia General de España, la primera y la más influyente de todas las de su género desde su publicación en 1601, no dudó en tratar de la aventura ultramarina de los portugueses como un capítulo más de las accio-

4 P. Pastelis: Catálogo de los documentos relativos a las Islas Filipinas existentes en el Archivo de Indias de Sevilla por $D$. Pedro Torres y Lanzas. Precedido de una erudita historia general de Filipinas, Barcelona, 1925-1934 (8 volúmenes), t. 7, 1, a parte, CLXXXIV-CLXXXV. Carta de juan Niño de Távora a Felipe IV. Manila, 8 julio 1632. (Apud R. Valladares. Castilla..., pág. 54).

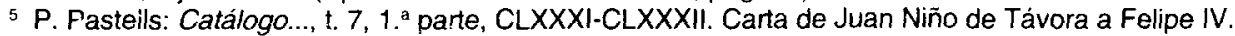
Manila, 30 julio 1630. (Apud R. Valladares: Castilla..., pp. 53-54).

6 F. Serrano Mangas: La encrucijada portuguesa. Esplendor y quiebra de la umión ibérica en las lndias de Castilla (1600-1668), Badajoz, 1994, pág. 162.

7 Cf. los estudios de C. R. Boxer: The Great Ship from Amacon. Annals of Macao and the Old Japan trade, 1555-1640, Lisboa, 1959; y The Poriuguese Seaborne Empire, 1415-1825, Londres, 1969. Para los destinos de la plata, cf. el reciente trabajo de M. Alfonso Mola y C. Martinez Shaw: "La era de la plata española en Extremo Oriente», Revista Española del Pacifico (en prensa). 
nes de los españoles, autorizado por la conciencia de que a partir de ahora las dos coronas iban a marchar juntas y a tener una trayectoria común. $Y$ los ejemplos podrían multiplicarse ${ }^{8}$.

Del mismo modo, los sucesivos titulares de la Monarquía Hispánica sentirian la necesidad de impulsar la historia de sus nuevos dominios, tomando iniciativas personales. Así, Felipe II, convertido en rey de Portugal, encargó a Diogo de Couto, guarda mor de la Torre do Tombo de Goa, la continuación de las famosas Décadas de João de Barros, interrumpidas en 1570, a fin de reconstruir las gestas de sus nuevos vasallos en tierras asiáticas. Por su parte, Felipe IV, por medio de Miguel de Noronha, conde de Linhares, virrey de la India portuguesa, encargó a António Bocarro, archivero real de Goa, la redacción de un informe de los estados lusitanos de Asia, que quedó plasmado en el famoso Livro de todas as Fortalezas e Plantas do Estado da Índia, datado en 1635, enriquecido al año siguiente con los bellos mapas de Pedro Barreto de Resende y precedido de una «Epístola a Su Majestad", que daba cuenta de las intenciones intervencionistas de la Corte en aquellos alejados territorios. De hecho, ya antes Constantino de Sá, gobernador de Ceilán, habia conseguido poner en las manos de Felipe IV su Descripção de Ceilão, escrita en 1624, con la intención de animar al monarca a emprender una acción militar que podía terminar con la expulsión de los holandeses de la isla de la canela ${ }^{9}$.

Un último campo donde la unión de las coronas dejaría sentir su influencia sería en el de la evangelización. En este sentido, si la empresa misionera en Filipinas fue acometida al unísono por los jesuitas y las órdenes mendicantes, fundamentalmente integradas por frailes españoles (agustinos, franciscanos y dominicos), fueron los portugueses los que dirigieron la evangelización de los restantes países asiáticos, situados en su zona de influencia y a los que habían llegado antes de la instalación hispana en Manila ${ }^{10}$. Incluso si Francisco Xavier, el apóstol de las Indias por excelencia, no era natural de Portugal, sino de Navarra, su misión, ordenada desde el reino lusitano, había sido objeto de una simbólica apropiación al ser trasladados sus restos mortales desde las costas chinas hasta la iglesia de los jesuitas en Goa (y ser enterrados, significativamente, junto con el bastón de mando de los virreyes lusitanos) ${ }^{11}$. Sin embargo, pronto los misioneros españoles empe-

\footnotetext{
8 Juan de Mariana: Historia General de España, Toledo, 1601. Dedicada a Felipe III, la intención del autor ya está presente en el prólogo: «Finalmente, no nos contentamos con relatar los hechos de un reino solo, sino los de todas las partes de España". Cf., asimismo, R. Valladares: Castilla.., pp. 1-6.

${ }^{9}$ Cf. R. Valladares: «Fenicios pero romanos. La Unión de las Coronas en Extremo Oriente (15801640)", en M. Alfonso Mola y C. Martínez Shaw (eds.): Oriente en Palacio. Tesoros asiáticos en las colecciones reales españolas, Madrid, 2003, pp. 114-120.

10 La bibliografia al respecto es ingente, por lo que nos limitamos a señalar el reciente volumen colectivo: A Companhia de Jesus e a Missionação no Oriente. Actas do Colóquio Internacional promovido pela Fundação Oriente e pela Revista Brotéria, Lisboa, 21 a 23 de abril de 1997, Lisboa, 2000.

11. La más extensa biografia de Francisco Xavier es la de G. Schurhammer: Franz Xaver. Sein Leben und seine Zeit, Friburgo, 1955-1973, 4 vols. (Hay versión española: Francisco Javier. Su vida y su tiempo, Bilbao, 1992). Sobre el destino del cuerpo del misionero jesuita, cf. M. Gade: "Saint François Xavier, l'incorruptible", en M. Chandeigne: Goa, 1510-1685. L'Inde portugaise, apostolique et commerciale, Paris, 1996, pp. 92-112.
} 
zaron a disputar a los portugueses la evangelización de provincias consideradas de su exclusiva responsabilidad, singularmente China y, sobre todo, Japón, donde los franciscanos españoles alcanzaron el martirio antes incluso que los jesuitas portugueses, en 1597, por orden de Toyotomi Hideyoshi. Esta presencia de los misioneros hispanos fue considerada una intromisión intolerable, generando un conflicto entre la empresa jesuítica lusitana y la empresa franciscana española, entre el «partido jesuítico-portugués» y el «partido castellano-mendicante», según la terminología de Emilio Sola ${ }^{12}$. Un conflicto que sólo el rey de España y Portugal podía dirimir, ya que las embajadas enviadas desde Japón a Occidente, primero por los señores cristianos de Arima, Omura y Bungo, a iniciativa de los jesuitas y vía Lisboa, y luego por Date Masamune, señor de Sendai, a iniciativa de los franciscanos y vía Acapulco, Veracruz y Sevilla, se dirigieron a la Corte, para ser recibidas, respectivamente, en 1584 por Felipe $1 \mathrm{y}$ y en 1615 por Felipe $1 \mathrm{II}^{13}$.

La misión de Etiopía pudo encontrarse ante un conflicto similar, pero el hecho de que fuese encomendada siempre con exclusividad a los jesuitas generó un escenario diferente y más distendido ${ }^{14}$. Los jesuitas eran una orden internacional, fundada por un español pero constituida por miembros de diversas procedencias. Por ello, los jesuitas actuaban en cuanto religiosos, sin atender al origen nacional de los misioneros. Ahora bien, la misión jesuítica en Etiopía se organizó desde un principio desde Portugal y estuvo integrada mayoritariamente por jesuitas lusitanos, justamente a fin de evitar conflictos en un territorio que caía bajo la esfera de influencia política de Portugal y que desde primera hora habia recibido ayuda militar lusitana y había aceptado la instalación de colonos portugueses. Incluso el camino para alcanzar Etiopía predisponía a dicha solución, ya que los religiosos debian salir en barcos portugueses desde Lisboa y llegar hasta Goa, desde donde se em-

12 E. Sola: «Relaciones entre España y Japón: Primeros contactos durante la gestión en Filipinas de los gobernadores Gonzalo Ronquillo de Peñalosa y Santiago de Vera (1580-1614). Manifestaciones iniciales de lo que será un "partido" castellano-mendicante en Extremo Oriente", Cuadernos de Investigación Histórica, n. ${ }^{\circ}$ (1977), pp. 37-57; e Historia de un desencuentro. España y Japón, 1580-1614, Alcalá de Henares, 1999.

13 Sobre las embajadas japonesas a España, cf. E. Sola: Historia..., pp. 30 y 128-145. Más recientemente, sobre la embajada a Felipe II, cf. J. Guillén Selfa: La primera embajada del Japón en Europa y en Murcia (1582-1590), Murcia, 1997. Y sobre la embajada a Felipe III, ct. M. Fernández Gómez: «Sevilla, encrucijada entre Japón y Europa. Una embajada japonesa a comienzos del siglo xvil (Misión Keicho)", Archivo Hispalense, n. 248 (1998), pp.33-60; y "La misión Keicho (1613-1620): Cipango en Europa. Una embajada japonesa en la Sevilla del sigio xvll", Studia Historica. Historia Moderna, n. 20 (1999), pp. 269-295.

14 La presencia exciusiva de los jesuitas en una región no siempre descartaba el conflicto, aunque si evitaba su exacerbación. En el caso del Paraguay, el obispo de Tucumán, Francisco de Vitória, que era de origen portugués, solicitó en 1585 al provincial de Brasil de la Compañía, Cristovão Gouveia, el envio de misioneros pará la evangelización de la provincia. Sin embargo, una vez llegada la expedición a Buenos Aires en 1587, supieron los jesuitas que el general de la Compañía, Claudio Acquaviva, había dispuesto que la misión debia enmarcarse en la provincia de Perú. Ante esta nueva situación las opiniones se dividieron, ya que, mientras los padres Manuel Ortega, João Saloni y Tomás Fields decidían continuar hasta el Paraguay, el padre Leonardo Arminio, el jefe del contingente, y el padre Estevão de Grã optaron por regresar a Brasil. (Cf. R. M. A. F. Gadelha: As missôes jesuiticas do Itatim. Um estudo das estruturas sócio-econômicas coloniais do Paraguai (séculos XVI e XVII), Rio de Janeiro, 1980 , pp. 189-208). 
barcaban hacia Masawa, para seguir por tierra hacia las tierras del emperador de los abisinios ${ }^{15}$.

Este derecho preferencial portugués sobre Etiopía les sería recordado reiteradamente a los soberanos españoles durante todo el periodo de la unión de las coronas. Así, en la entrada de Felipe II en Lisboa, el 27 de junio de 1581, el programa iconográfico de las arquitecturas efímeras incluía alusiones a la Orden de Cristo (que tenía encomendada la gestión espiritual de los territorios de Ultramar) y a las posesiones de Portugal que el nuevo monarca debía defender, entre las cuales, junto a Goa, Cananor, Cochin, Chaul, Diu, Ceilán, Malaca, Ormuz y Brasil, figuraba también Etiopía ${ }^{16}$. Lo mismo ocurriría con la entrada de Felipe III en la capital lusitana en 1619, cuando el programa iconográfico insistió especialmente en las obligaciones de los gobernantes para con el imperio ultramarino, mientras un jesuita portugués, António de Sousa, ponía en escena una obra dramática sobre Manuel el Afortunado ${ }^{17}$.

De este modo, la empresa jesuítica de Etiopía pudo mantenerse sin tensiones internas por cuestiones de nacionalidad, pese a la ambigüedad que podía provenir tanto de la internacionalidad de la Compañía, como del ejercicio del padroado por el titular de la Monarquía Hispánica. Ya antes de la unión de las coronas, Ignacio de Loyola, primer interesado en la evangelización de aquellas tierras de antigua cristiandad, se había mostrado prudente a la hora de elegir a los miembros de la

15 El relato general de la misión jesuita en Etiopia puede seguirse a través de tres obras esenciales: Girmah Beshad y Merid Wolde Aragay: The Question of the Union of the Churches in Luso-Ethiopian Relations (1500-1632), Lisboa, 1964; P. Caraman: The lost Empire: the Story of the Jesuits in Ethiopia, Londres, 1985 (Hemos utilizado la traducción francesa: L'empire perdu. L histoire des jésuites en Ethiopie, París, 1988); y H. Pennec: Des Jésuites au royaume du Prêtre Jean (Ethiopie). Stratégies, rencontres et tentatives d'implantation, 1495-1633, Paris, 2003.

${ }^{16} \mathrm{Cf}$. N. Senos: “'Na esperança de vossa real presença desejada'. El arte y un poder ausente en la Lisboa filipina, 1580-1640", Reales Sitios, n. ${ }^{\circ} 158$ (2003), pp. 48-61 (la cita, en pág. 59). "Y, para que quede clara la extensión real del Mar Océano cuya guarda Neptuno entregaba a Felipe, una serie de estatuas alegóricas dispuestas entre el arco de los alemanes y las puertas de la Ribeira representaba las siguientes entidades: la Orden de Cristo, a la que estaba encomendada, desde tiempos del Infante don Enrique, la gestión espiritual de todos los territorios ultramarinos; la unión de las Indias Occidentales (de parte de las cuales Felipe era ya señor) con las Indias Orientales (sobre las que desde entonces reinaba también) representadas por dos mujeres que se abrazaban sobre el globo del mundo; $y$, finalmente, una serie de mujeres representando las posesiones extraeuropeas de Portugal: Goa, Cananor, Cochin, Chaul, Diu, Ceilán, Malaca, Ormuz, Etiopia y Brasil’ (La descripción se basa en la crónica de A. Guerreiro: Relação das Festas que se Fizeram na Cidade de Lisboa na Entrada de El-Rei D. Felipe, Primeiro de Portugal, edición moderna, Lisboa, 1950).

${ }^{17} \mathrm{Cf}$. N. Senos: “'Na esperança de vossa real presença desejada'...” (la cita, en pág 60): «El programa iconográfico revisita también otras figuras de la historia de Portugal, atribuyéndoles sentidos que las integran en una narrativa coherente y que reformulan la memoria nacional: Martim Moniz, que dio la vida por la conquista; el Infante Santo, que dio la vida por lo conquistado, prefiriendo morir en el cautiverio de Tánger que trocar su libertad por la plaza de Ceuta; Don Constantino de Bragança, que despreció las riquezas asiáticas para que triunfase la religión; Don João de Castro que, a falta de mayor riqueza, dejó una mecha de su propia barba como garantía del préstamo que contrajo para la reconstrucción de las murallas de Diu. A esto hay que añadir que más tarde Felipe Ill asistió a la tragicomedia “D. Manuel, conquistador do Oriente", escrita por el padre jesuita António de Sousa". (Aquí la descripción se basa en el libro de G. Kubler: A Arquitectura Portuguesa Chã. Entre as Especiarias e os Diamantes, 1521-1706, Lisboa, 1988). 
Compañia destinados a Etiopía, para todos los cuales se ocupó en redactar las pertinentes instrucciones. Así, la misión enviada desde Lisboa en 1554 contaba a su frente con el patriarca portugués João Nunes Barreto y con dos obispos auxiliares, el portugués Melchior Carneiro y el español Andrés de Oviedo, que se convertiria más tarde en patriarca a la muerte de su antecesor y que fue el único en alcanzar las tierras del emperador abisinio, por decisión del propio virrey de la India, que no tomó en consideración la cuestión de los orígenes a la hora de elegir al expedicionario entre los jesuitas llegados a Goa. Como es sabido, esta primera misión jesuítica concluyó en 1595, sin haber obtenido los frutos de la conversión al catolicismo de la Iglesia monofisita ${ }^{18}$.

Antes de que se produjese este final, ya se habia preparado una segunda misión, que se desarrolló por entero durante el periodo de la unión de las coronas, lo que le confiere unos rasgos singulares. Así, quizás no sea pura casualidad el hecho de que el manuscrito redactado por Ruy González de Clavijo sobre la embajada enviada por Enrique III de Castilla a Samarcanda en la primera década del siglo $\mathrm{XV}$, se publique precisamente en Sevilla en 1582, sino que responda a un renovado interés español por resucitar sus antiguos contactos con el mundo oriental. En efecto, Gonzalo Argote de Molina, el erudito responsable de la edición, nos explica, por un lado, en su dedicatoria a Antonio Pérez, el secretario de Felipe II, que ha editado el manuscrito para suplir en lo referente a Tamerlán la incompleta crónica del portugués João de Barros ( Entre tanto que no llega a nuestra noticia la historia del Tamorlán que João de Barros nos prometia..."), mientras, por otro, en el texto del discurso compuesto para acompañar la narración, nos recuerda los motivos de la embajada: “Escribe Gonzalo Fernández de Oviedo... (que Enrique III), deseando la amistad y comunicación de los príncipes del universo, procuró tener sus embajadores en las cortes de los reyes cristianos, sus vecinos, y en las del Preste Juan, señor de la India Oriental, del Soldán de Babilonia, del gran Turco Bayaceto y del gran Tamurbec, por común nombre llamado el Tamorlán ${ }^{19}$.

Si el episodio señalado puede no revestir mayor importancia, lo que sí es cierto es que la iniciativa de la segunda misión partió directamente de Felipe II, que, según la autorizada opinión de Philip Caraman, "se había convertido en el supremo protector de la actividad misionera en Oriente tras la unión de las dos coronas en 1580 " y que "no se desinteresó nunca de Etiopía, ya que tenía la preo-

18 P. Caraman: L'empire perdu..., pág. 29, nota 5, llama la atención sobre un cuadro conservado en la sacristía de la iglesia del Gesú de Roma, que representa a San Ignacio de Loyola en el acto de entregar las constituciones de la Compañía de Jesús al papa Paulo III y en el que figuran retratados el monje etiope Piedro (instalado en Roma desde 1540) y el cardenal Luigi Farnese, que se habia convertido en su protector.

19 Ruy González de Clavijo: Historia del Gran Tamorlán e itinerario y cnarración del viage y relación de la Embaxada que Ruy Gonçalez de Clavijo le hizo por mandado del muy poderoso Señor Rey Don Henrique el Tercero de Castilla, Sevilla, 1582 (edición de Gonzalo Argote de Molina, que incluye El gran discurso hecho por Gonçalo Argote de Molina sobre el Itinerario de Ruy González de Clavijo). Hay edición moderna de F. López Estrada, Madrid, 1943. 
cupación de llevar al emperador a la unión con la Iglesia romana y de hacerlo su aliado contra Turquía». En efecto, si en 1584 el Rey Prudente había recibido en EI Escorial la embajada de los daimíos cristianos, pocos años más tarde, en 1588 había decidido el restablecimiento de la misión jesuítica en Etiopía, que en aquel momento se hallaba reducida a una sola persona, el padre Francisco Lopes. Para ello, ordenó al virrey, Don Duarte de Meneses, que estudiase la mejor vía para entrar en el territorio, bien por Malindi, bien por Alejandría, bien por Masawa, incluso si era necesario ocuparla militarmente, y después le envió instrucciones para que presionara al provincial de la Compañía en Goa, el padre Pero Martins, para que mandase a dos misioneros a Etiopia ${ }^{20}$.

La elección recayó en dos jesuitas españoles. El primero fue el padre Antonio Montserrat, un catalán nacido en Vic que ya se había distinguido por su actividad en la corte de Akbar, en el Imperio Mogol ${ }^{21}$. El segundo fue el padre Pedro Páez, un religioso castellano cuya biografía, por cierto, ignoran la mayor parte de los libros dedicados tanto al imperio portugués como a la historia de Etiopía 22 .

20 P. Caraman: L'empire perdu..., pp. 49 ss. Del constante interés manifestado por Felipe II respecto a la evangelización de Etiopía da cuenta una carta del monarca (firmada por su hijo, el futuro Felipe III) dirigida el 26 de enero de 1598 al virrey de la India. Francisco da Gama, y recientemente exhumada por Geoffrey Parker: «Todavía en 1598, con la muerte acercándose veloz, el rey halló tiempo para reprender al virrey de la India portuguesa por no haberle remitido unas cartas del emperador de Etiopía recibidas en Goa, porque nadie había sido capaz de traducirlas al portugués. "No falta aquí gente que pueda hacerlo", escribió con irritación, y ordenó que, en el futuro, cualquier comunicación similar le fuera enviada sin falta». (G. Parker: La gran estrategia de Felipe II, Madrid, 1998, pág. 121).

21. Cf. S. N. Banerjee y J. S. Hoyland (transcription and notes): The Commentary of Father Montserrate, S. J., on his Journey to the Court of Akbar, Londres, 1922. (Reeditado en Nueva Delhi, 1992).

22 Entre las obras generales consagradas al imperio portugués, no ofrecen noticias, por ejemplo, las de C. R. Boxer: The Portuguese...; A. J. R. Russell-Wood: The Portuguese Empire, 1415-1808. A World on the Move, Manchester, 1992; o S. Subrahmanyam: The Portuguese Empire in Asia, 1500-1700. A Political and Economic History, Singapur, 1993. Y, entre las dedicadas a la historia moderna de Africa en general, nada dice la de J. lliffe: Africans. The History of a Continent, Cambridge, 1995; la Cambridge History of Africa, Cambridge, 1975, vol 4, pp. 548-549, tampoco ofrece datos biográficos del misionero español, aunque sí noticias sobre su predicación en Etiopia; la UNESCO General History of Africa, París, 1981-1993, acierta en la nacionalidad española de Pedro Páez, aunque no en la de Andrés de Oviedo (cuyo nombre se transcribe en italiano: "Andrea da Oviedo") ni en la de Afonso Mendes, al que se alude como «Alphonso Mendez, el nuevo obispo español» (ed. francesa abreviada, vol. V, pp. 476-477); y J. Ki-Zerbo: Historia del Africa negra. I. De los origenes al siglo xix, Madrid, 1980, pp. 433-435, atribuye a un imposible "fraile llamado Méndez" la evangelización anterior a Pedro Páez, al que se refiere en estos términos: “el prodigioso padre Páez, que no aprobaba los excesos de Méndez", refiriéndose sin duda a Afonso Mendes, cuya actividad en Etiopía es posterior a la muerte del misionero español. Por su parte, los historiadores que se han ocupado especificamente de Etiopía, si bien se acercan más a la verdad, tampoco alcanzan la exactitud: H. G. Marcus: A History of Ethiopia, Berkeley, 1994, pp. 39-40, nombra a Pedro Páez como jesuita español, pero concede la misma nacionalidad al patriarca Afonso Mendes (escrito aqui Mendez); P. B. Henze: Layers of Time. A History of Ethiopia, Londres, 2001, pp. 92-100, señala a Pedro Páez como de origen español ("Spanisn-origin Father»), sin pronunciarse sobre la nacionalidad de los demás jesuitas, cuyos nombres se transcriben como Andre da Oviedo y Alfonso Mendes, respectivamente; y, por último, D. Alder: The Making of an Enterprise. The Society of Jesus in Portugal, Its Empire, and Beyond, 1540-1750, Stanford, Ca., 1996, pág. 154, hace nacer a Pedro Páez en Alcocer, en la diócesis de Toledo. Por otra parte, son muchas las reseñas biográficas que hacen a Pedro Páez natural de Olmedo. En España, finalmente, ni siquiera un autor tan bien informado como R. Valladares: Castilla..., menciona al religioso español, aunque si se refiere a casi todos los demás misioneros jesuitas en Abisinia (pp. 57-60). 
Pedro Páez habia nacido en 1564 en Olmeda de la Cebolla (hoy Olmeda de las Fuentes), en el obispado de Toledo y hoy dentro de la comunidad autónoma de Madrid, y se habia formado en la Universidad de Coimbra antes de realizar su noviciado en Belmonte, donde tuvo como amigos a Fernando Santarén de Huete (que sería martirizado por indios mexicanos en 1616), a Luis de Guzmán (que a pesar de avanzar su nombre como misionero voluntario al Japón nunca llegó a salir de la Península y hubo de escribir de segunda mano su conocida Historia de las Misiones de la Compañía de Jesús en la India Oriental, en la China y en Japón desde 1540 hasta 1600, publicada en Alcalá de Henares en 1601) y a Tomás Ituren, que fue el principal destinatario de sus cartas desde Oriente. En 1588, con veinticuatro años, ya está en Goa, a donde había llegado a bordo de la nave São Tomé y desde donde escribe una carta conteniendo algunos de los escasos datos que conocemos acerca de los primeros años de su vida. En 1589, y tras ser ordenado sacerdote Pedro Páez, los dos jesuitas españoles parten para Masawa con destino a Etiopía. Como es bien sabido, esta primera expedición termina con el cautiverio de los dos jesuitas, el tardío rescate de ambos y su posterior regreso a Goa en 1596, aunque esta dura experiencia les permite ser los primeros europeos en recorrer el Hadramaut ${ }^{23}$.

En 1603, y después de otras peripecias, Pedro Páez se encuentra en Etiopía, según sabemos por su propio testimonio: «Depois que entrei em este Imperio d' Ethiopia, que foi em Mayo de $1603{ }^{24}$. Es ahora cuando se inicia su verdadera labor misional, con el objetivo final de conseguir el abandono del monofisismo por la Iglesia etíope y su ingreso en el seno de la Iglesia Católica de Roma. No vamos a detenernos en la actividad de Pedro Páez en Abisinia, sino sólo a recordar algunos hitos importantes para nuestros propósitos. Muy pronto aprende el amárico y el geez, lo que le sirve para traducir del portugués a la primera de estas lenguas, la efectivamente hablada en el país, la cartilla o breve resumen de la doctrina cristiana, con la colaboración del padre portugués João Gabriel y de otro portugués descendiente de los expedicionarios de Cristovão da Gama. Posteriormente adquiere gran influencia en la corte imperial, primero con Za Dengel (depuesto en 1604) y después con Susenios (1607-1632), que terminará por declarar en 1622 su voluntad de convertirse al catolicismo, como ya había hecho su hermano Sela Krestos. Antes, será el primer europeo en visitar las fuentes del Nilo Azul, en 1618. A partir de 1607, y por encargo del padre provincial, compone su Historia de Etiopia, en realidad un texto que trata además de la arqueología, geografía, etnologia, teología e historia natural de Abisinia. Muere agotado a los 58 años, en mayo de 1622, después de recibir la confesión de Susenios anunciándole su conversión al catolicismo ${ }^{25}$.

${ }^{23}$ Los datos biográficos proceden de P. Caraman: L'empire perdu..., especialmente pp. 39-67.

$2^{a}$ Pero Pais: História da Eiiópia. Reprodução do códice coevo inédito da Biblioteca Pública de Braga, Oporto, 1945-46. (Introdução: Elaine Sanceau. Notícia bio-bibliográfica: Alberto Feio). La cita, en t. I, pág. 3.

${ }_{25}$ Sobre los viajes de Pedro Páez, cf. G. Bishop: A Lion to Judah. The Travels and Adventures of Pedro Páez, S. J., Bourne, 1998 (Hay traducción española: Viajes y andanzas de Pedro Páez, primer europeo en las fuentes del Nilo, Bibao, 2002). 
La primera intervención cortesana de Pedro Páez prefigura ya toda su actuación posterior. El emperador Za Dengel le encomienda la redacción de sendas cartas dirigidas al papa Clemente VIII y al rey Felipe III. El jesuita le recomienda que no lo haga dadas las consecuencias de otra carta anterior, solicitando a Felipe II el envío de cañones y mosquetes, que, maliciosamente interpretada por sus enemigos como una prueba de su conversión al catolicismo, había originado una sublevación. Sin embargo, ante su insistencia Pedro Páez escribe la misiva a Felipe III, donde se pide el envío de artesanos, misioneros y soldados, con el fin de emprender la conquista de Masawa frente a los turcos y de atacar a los oromos, ofreciendo a cambio el matrimonio de su hijo con una hija del monarca español. Tal como temía el jesuita, estalla una nueva revuelta, en cuyo transcurso muere $\mathrm{Za}$ Denge ${ }^{26}$.

En los años siguientes, Pedro Páez consigue ganarse la confianza tanto del emperador Susenios (coronado en Axum, en marzo de 1608) como de su hermano Sela Krestos, un verdadero admirador del jesuita que se convertiría al catolicismo hacia 1612. En esta tesitura, Pedro Páez continúa ejerciendo su labor de mediación entre el emperador, por un lado, y el papa y el rey de España y Portugal, por otro. Así, en 1609 una carta del papa Paulo V transmitía a Susenios su confianza de que Felipe III, "el poderoso rey católico de las Españas» acogería su recomendación (hecha a través del nuncio apostólico en Madrid) de enviar a Etiopía una "ayuda efectiva". Sin embargo, dos años después, en 1611, la carta de Felipe III que llega a Dancaz solamente expresa el deseo de mantener relaciones amistosas con el emperador y la petición de que éste siga protegiendo a los $\mathrm{mi}$ sioneros y a los colonos portugueses ${ }^{27}$.

Los años que median entre 1610 y 1615 son años de grandes expectativas entre los jesuitas. En efecto, al tiempo que se esperan los primeros resultados de la reciente instalación de misiones en Persia, Ceilán, Bengala y Madura, circulan excelentes noticias acerca de la posibilidad de una pronta conversión de la India, China, Japón y Etiopia ${ }^{28}$. En la India, los misioneros confiaban en revalidar bajo Jahangir la oportunidad que les había ofrecido el difunto Akbar, mientras en China parecía llegado el momento de recoger los frutos de las semillas sembradas por el padre Matteo Ricci y en Japón se preparaba la embajada a Felipe III, que efectivamente habria de alcanzar España a fines de 1614. En Etiopía, también Susenios

${ }^{26}$ El relato de la actuación de Pedro Páez ante Susenios sigue los trabajos ya citados de Girmah Beshad y Merid Wolde Aragay: The Question..., especialmente pp. 69-104, y P. Caraman: L'empire per$d u$.., especialmente pp. 91-184, en gran parte coincidentes, aunque las interpretaciones sobre el significado político y religioso sean distintas y las valoraciones a veces contrapuestas. El texto de los autores etiopes es el utilizado también por D. Crummey: Land and Society in the Christian Kingdom of Ethiopia. From the Thirteenth to the Twentieth Century, Addis Ababa, 2000, pp. 67-72.

${ }_{27}$ P. Caraman: L'empire perdu..., pp. 119-120.

${ }^{28}$ Cf. D. Alden: The Making..., especialmente pp. 130-158. La evangelización de Persia, que por entonces estaba en manos de carmelitas y agustinos, también habia entrado, aunque fuera de modo subordinado a! objetivo principal de la alianza política y militar, en las instrucciones dadas a Garcia de Silva y Figueroa, responsable de la embajada que Felipe III habia enviado al shah Abbas. (Cl. C. Alonso: La embajada a Persia de Don Garcia de Silva y Figueroa (1612-1624), Badajoz, 1993). 
organizaba, a fin de solicitar ayuda militar de Felipe III, una embajada que se dirigiría en 1613 al sur del pais con intención de encontrar una ruta hacia Europa que evitase la amenaza otomana, aunque finalmente la expedición regresaría sin haber conseguido ni siquiera aproximarse a su objetivo ${ }^{29}$.

Defraudadas las expectativas en todas partes, hay que esperar hasta el año 1617 para que Felipe III se comunique con el emperador abisinio, prometiéndole de nuevo apoyo militar, pero a condición de que la situación en la India permita el envío de tropas, cosa que nunca sucedió. La buena voluntad del rey español se manifestó tan sólo en las instrucciones enviadas al virrey en Goa para que estudiase la posibilidad de acceder a Etiopía por Malindi, el capitán de cuya fortaleza recibe órdenes al respecto, también sin resultados efectivos. Son los años que preceden a la conversión de Susenios y también a la muerte de Pedro Páez.

Los años siguientes asisten a un cambio radical en la política interior de Etiopía, que, bajo la dirección del nuevo emperador Fasiladas, significa el fin de los proyectos de Susenios de vincular la Iglesia monofisita de Abisinia a la Iglesia católica de Roma. Ahora bien, una parte de la responsabilidad en estos hechos cabe atribuirla a la desaparición de Pedro Paéz y a la entrada en escena del patriarca Afonso Mendes, que en diez años va a ver arruinada toda la labor de las dos décadas anteriores y condenada al fracasc la misión jesuítica en el reino del Preste Juan. El nuevo patriarca se había ganado ei favor del soberano español, Felipe IV, tras un sermón pronunciado en 1621 ante la Corte en la ciudad portuguesa de Evora. El rey, en virtud del padroado, le había promovido a tan alta dignidad, sin haber consultado previamente ni al papa ni al general de los jesuitas, lo que generó toda una serie de recelos, ya que a unos no le parecia persona idónea, mientras otros denunciaban la irregularidad del nombramiento ${ }^{30}$. Como es bien sabido, su llegada contribuirá a la caída de Susenios y al entronizamiento en 1632 de su hijo Fasiladas, que finalmente acabará decretando la expulsión de todos los jesuitas en 1634, lo que no sólo significará el fin de la misión jesuítica, sino el cierre de Etiopía a toda influencia europea durante dos siglos. El fracaso de la misión de Etiopía fue, tanto para la Compañía de Jesús como para Portugal, un duro golpe, que se vio potenciado negativamente por el deterioro de la situación en Japón, que culminó con el recrudecimiento de la persecución contra los cristianos y la definitiva expulsión de todos los portugueses en 1639, un año antes de la sublevación bragancista que terminó con la unión de las coronas.

En este contexto de cambio de escenario histórico, puesto de manifiesto por el fracaso evangelizador de la Compañía y por el declive lusitano en Asia (pérdida de

${ }^{29}$ Cf. para Japón: C. R. Boxer: The Christian Century in Japan, 1549-1650, Berkeley, 1967; para la India, J. Correia-Afonso: Jesuit Letters from the Mughal Court: The first jesuit mission to Akbar (1580-1583), Anand, 1980; y para China, J.-P. Duteuil: Le mandat du ciel. Le rôle des jésuites en Chine, París, 1994.

${ }^{30}$ P. Caraman: L'empire perdu..., pág. 191. 
Ormuz, expulsión de Nagasaki, retroceso en Ceilán, pérdida de Malaca), sobre el marco de la restauración portuguesa, la misión de Etiopía puede servir de observatorio para captar algunas de las claves de este momento que coincide con el fin de la unión de las coronas.

Pedro Páez había escrito su Historia de Etiopía a instancias del provincial de la orden, con el fin de dar cuenta, entre otras cosas, del pasado y el presente del país donde se desarrollaban las actividades misioneras de los jesuitas. Su composición no deja de ser un espejo de las muchas virtudes del religioso español. Por un lado, hay que destacar, primero, su rigor como investigador, que se vio ayudado por su conocimiento de las lenguas del pais, incluyendo el litúrgico geez, lo que da una extraordinaria solidez a la obra, que así podrá servir de base a todos los escritos posteriores sobre Abisinia.

En segundo lugar, hay que resaltar su defensa de la verdad, ya que la obra surgía también (y quizás en primer lugar) como una respuesta contra las fabulaciones contenidas en la Historia de la sagrada orden de Predicadores en los remotos reynos de la Etiopía, publicada en Valencia, en 1611, por el dominico español Luis de Urreta, que, empeñado en ofrecer una imagen distorsionada de la realidad abisinia, llegaba a sostener la perfecta catolicidad de los etíopes, gracias a la predicación de los dominicos, que desde el siglo xIII habrían fundado en Abisinia toda una serie de conventos que seguian en pie hasta sus propios días, lo que implicaba la completa descalificación, por inútil, de la obra de los jesuitas en las tierras del Preste Juan ${ }^{31}$. Sin embargo, fiel a su espíritu de moderación, Pedro Páez no entra en una querella entre órdenes religiosas rivales, pese a lo descabellado de las afirmaciones de Urreta, sino que, por el contrario, se preocupa por disculpar al fraile dominico, al que, en lugar de mala fe, atribuye simplemente un exceso de ingenuidad por haber confiado a ciegas en su informante, João Balthasar, sobre el que hace recaer toda la responsabilidad, como destaca en el prólogo al lector: «...no principal falarei de vista e experiencia e não por informaçoens como as de João Balthasar... ${ }^{32}$.

Por último, el autor escribe su obra en portugués, aceptando asi el carácter lusitano de la empresa misionera en Etiopía, pese a ser desempeñada por una orden de carácter internacional como era la jesuítica, que en los años de su mandato contaba además, junto a dos padres portugueses, con un padre romano y otro napolitano. Por si esto fuera poco, en el citado prólogo, Pedro Paéz declara expresamente su imparcialidad respecto de portugueses y de abisinios: «...e em tudo o

31 Luis de Urreta: Historia de la sagrada orden de Predicadores en los remotos reynos de la Etiopia. Trata de los prodigiosos Santos, Mártyres y Confessores, Inquisidores apostólicos, de los conventos de Plurimanos, donde viven nueve mil frayles, del Alleluya con siete mil, y de Bedenagli de cinco mil monjas, con otras grandezas de la religión del Padre Domingo, Valencia, 1611. Previamente, el dominico había publicaco otra obra sobre Abisinia: Historia eclesiástica, política, natural y moral de los grandes y remotos Reynos de la Etiopía, monarchía del Emperador llamado Preste Juan de las Indias. Con la Historia de Predicadores en los remotos Reynos de la Etiopía, Valencia, 1610.

32 Pero Pais: História da Etiópia..., pág. 11. 
que escrever, ora toque aos Portugueses, ora aos de Ethiopia falarei desenteressadamente con clareza e sem encarecimentos; porque demais de ser religioso, a quem pertence dizer singelamente a verdade do que souber, nem pera engrandecer aquelles me poderá mover a carne e sangue, nem pera desfazer em estes me incitará desgosto particular, antes lhes tengo muitas obrigaçoens, porque do ponto que entrei em suas terras, sempre me fizerão muitas honras e merces sobre merces...". Es decir, empresa jesuita, pero portuguesa, aunque fuera llevada por un castellano; y la verdad antes que cualquier inclinación particular ${ }^{33}$.

Ahora bien, los jesuitas lusos eran jesuitas pero portugueses y entendían que la obra misionera en las regiones bajo influencia de la Corona portuguesa se inscribian en una suerte de historia salutis per Lusitanos, por lo que tendían a acentuar el doble carácter cristiano y portugués de la evangelización. Esta percepción providencialista se dio en todos los territorios, como puede demostrar el ejemplo del padre António de Andrade, que en su Novo Descobrimento do Gram Catahayo ou reinos do Tibet, publicado en 1626 a raíz de la llegada de los jesuitas a aquella región a partir de su misión en Agra, escribe, refiriéndose precisamente a los éxitos de la misión de Etiopía: "Com muito mor razão deve o mundo festejar a redução do grande império de Etiópia à obdiència da Santa Igreja Católica Romana: império tão grande que ele só é igual ou maior que toda nossa Europa, pois tem de largo quinhentas léguas, e de comprido setecentas. Ambas estas empresas tão gloriosas (Tibet y Etiopía) guardou a divina providència, por tantos séculos, para os generosos espíritos portugueses, e para o espírito, e zelo das almas dos reverendos padres da Companhia de Jesus...". O sea, patriotismo portugués unido a patriotismo jesuítico ${ }^{34}$.

La revisión de la obra de Pedro Páez después de su muerte ofrece nuevos materiales sobre la inclusión de la misión jesuítica dentro del patrimonio de la expansión portuguesa. Así, el padre Manoel de Almeida escribe aproximadamente entre 1628 y 1644 una nueva História de Etiópia, para la que se vale, llegando casi a la copia literal, de la obra de Pedro Páez ${ }^{35}$. Ahora bien, redactar la historia de Etiopia desde el principio por alguien que no reunia ni de lejos las cualificaciones del jesuita español, y no conformarse con el mero añadido de la crónica de los hechos acaecidos desde 1622, exigía una justificación, que Almeida ofrece al provincial, el padre Mutio Vitelleschi, en una carta que le dirige en 1639, cuando la misión etiópica se habia derrumbado: «En tanto que español, Páez no tenía un dominio perfecto del portugués, lengua en la que escribia; habia olvidado el español, que no habia hablado desde hacía largos años, pero empleaba a menudo el árabe, el turco, el amá-

33 Ibidem.

34 António de Andrade: Novo Descobrimento do Gram Catahayo ou reinos do Tibet, Lisboa, 1626, $f^{\circ}$ $15 v^{\circ}$. Sobre el viaje del jesuita portugués, cf. C. Wessels: Early Jesuit Travellers in Central Asia, Delhi, 1998 (la edición original es de 1924), pp. 35-57.

35 Manoel de Almeida: História de Etiópia, en C. Beccari (ed.): Ferum Aethiopicarum Scriptores Occidentales Inediti a saeculo XVI ad XIX, Roma, i903-1917, vols. V, VI y VII. (La obra de Pedro Páez ocupa los volúmenes II y III de la misma colección). 
rico y la otra lengua, la de los libros de Etiopía, lenguas que había aprendido. Por estas razones, con ocasión de la reunión que tuvimos en Gorgorá a comienzos del año 1626, el superior, que era entonces el padre António Fernandes, me encargó, con asentimiento de los otros padres, describir este Estado cristiano, para servicio e Dios y para difundir su conocimento" ${ }^{36}$. ¿No parece un argumento más bien baladí la falta de galanura en el portugués de Pedro Páez? ¿No suena a maniobra de la confusión la combinación de la falta de perfección de la lengua portuguesa con los otros argumentos relativos al olvido del español y al conocimiento de otros idiomas, es decir el hacer pasar las virtudes como deméritos, teniendo en cuenta que precisamente el dominio del amárico y del geez (la «lengua de los libros") era lo que le confería a Pedro Páez su superioridad como historiador? Quizás podría pensarse que llevamos muy lejos las deducciones a partir de indicios demasiado débiles, si no fuera porque pronto se asistirá a una nueva maniobra editorial, que se justificará con los mismos argumentos ${ }^{37}$.

En efecto, en 1660 aparece en Coimbra la obra del padre Baltasar Teles titulada História Geral de Etiópia a Alta ou Preste loam, que viene a ser una nueva versión de las obras anteriores de Pedro Páez y de Manoel de Almeida con algunos añadidos de cosecha propia ${ }^{38}$. Aquí vuelve a plantearse la cuestión de la necesidad de la obra dada la escasa aportación a los dos textos originales, y ello hasta tal punto que las piezas preliminares abundan en discursos justificativos de la oportunidad de la publicación. El propio autor da principio a esta literatura exculpatoria, señalando la génesis del libro en su dedicatoria al general de la Compañía, el padre Gosuvino Nikel: «...tendo sido seus trabalhos gloriosíssimos e estando escritos pelo muy veneravel Padre Manoel d'Almeyda, de boa memoria, e nam acabando de ter a luz do prélo, me mandou Vossa Paternidade, movida de sua grande vigilancia, que eu os emmendasse et aperfeyçoasse ${ }^{39}$.

A renglón, seguido, Francisco Manuel de Melo, el conocido historiador de la guerra de Cataluña, que (no hay que olvidarlo) fue encarcelado por el Conde Duque de Olivares como sospechoso de deslealtad, para convertirse más tarde en activo colaborador de la causa bragancista en Portugal, también se ve obligado a defender al padre Teles contra los detractores que le acusaban de ser un mero

${ }^{36}$ Apud P. Caraman: L'empire perdu..., pág. 182. La traducción al castellano es nuestra.

37 Al margen de la rivalidad misionera entre españoles y portugueses, hay que contar también con el factor más general de la extendida animadversión que por esos años sentían contra los españoles los portugueses de las Indias Orientales, que, al decir del embajador enviado por Felipe III a la corte del sha Abbas el Grande, "no sólo aborrecen la unión con la Monarquia de España, pero por ningún caso quieren nombrarse ni ser tenidos por españoles" (Garcia de Silva y Figueroa: Comentarios de la Embajada que de parte del Rey de España Don Felipe III hizo al Rey Xa Abas de Persia, Madrid, 1903-1905, t. II, pp. 360-361).

${ }_{38}$ B. Teles: Historia Geral de Ethiopia a Alta ou Preste loam e do que nella obraram os Padres da Companhia de Jesus. Composto na mesma Ethiopia pelo Padre Manoel d'Almeyda, natural de Vizeu, Provincial e Visitador que foy na India. Abreviada con nova releyçam e methodo pelo Padre Balthezar Telles, natural de Lisboa, Provincial da Provincia Lusitana, ambos da mesma Companhia, Coimbra, 1660. Sobre la obra de Baltasar Teles, cf. I. Carneiro de Sousa: A crónica como missão. A 'História da Etiópiaa-Alta ou Preste João' do Padre Baltasar Teles (1660), Oporto, 1998.

${ }^{39} \mathrm{~B}$. Teles: Historia Geral de Ethiopia... Dedicatoria $\left(f^{\circ} \| 1 \mid v^{\circ}\right)$. 
copista de los escritos de Pedro Páez, Manoel de Almeyda y el patriarca Afonso Mendes, aduciendo metafóricas y vacuas variaciones sobre el tema de ser el todo distinto al conjunto de las partes: "Escreveu o Padre Mestre Baltasar Teles esta História pelas memórias que da Etiópia deixaram escrito o Padre Manuel de Almeida, o Padre Pero Pais, o Senhor Patriarca D. Afonso Mendes. Esta é a primeira verdade que logo te inculca nosso Autor, no Rosto, no Prólogo e no Livro. Não cuide algum ignorante que, por esta causa, tem esta obra menos sua. Quem diria que deixa a fábrica de ser do Arquitecto elegante, porque os materiais nasceram en poder alheio, e por trabalho alheio se ajuntaram: não deixava o Capitólio de ser de Roma, posto que os mármores viessem de Corinto... ${ }^{40}$.

El último texto preliminar es precisamente el del patriarca Afonso Mendes, que lo escribe en Goa el 29 de setiembre de 1655, poco antes de su muerte ${ }^{41}$. La justificación en este caso es más extensa y se articula en varias partes. La primera, después de recordar que la génesis de la obra se remonta a una iniciativa suya urgiendo al "reverendo padre geral» a encargar la redacción del libro a Baltasar Teles, se dedica a señalar el arcaismo de las anteriores crónicas sobre la empresa portuguesa en Etiopía: «Que assim como as arvores se mudam todos os annos cahindolhe as primeras folhas, e nascendo outras em seu lugar, assim morre a primeyra idade das palabras, e as que depoys nasceram só florecem e tem vigor. Esta consideraçam presente espertou en mim hun pensamento, e desejo de ver posta en semelhante estilo a Historia de Ethiopia, que por morte dos Pares Pero Pays, quasi primeyro conquistador d'aquella empreza, e do Padre Manoel d'Almeyda, Visitador d'ella, estava no mesmo estado em que estava a Chronica de Portugal nos tempos passados, sem haver quem puzesse os olhos nella, nem quizesse tirar a luz heroycas façanhas que nella obráram os quatrocentos Portuguezes, que lá entraram no anno de mil e quinhentos e quarenta e hum...". O sea, los escritos anteriores no recogían de modo suficientemente expresivo las gestas portuguesas, especialmente la expedición militar de Cristovão da Gama, recuerdo intencionado en un hombre que había urgido a Felipe IV a una intervención armada para restaurar la misión jesuítica en Abisinia.

En segundo lugar, el padre Mendes repite los argumentos de Manoel de Almeyda frente a la lengua empleada por Pedro Páez, cuya entrada en Portugal retrasa, olvidándose de sus años en Coimbra, y a quien además confiere el sacerdocio antes de tiempo: «...os sobreditos dous Padres terem passados, notados e trasladados todos os livros de Ethiopia, que tocam en historia, ou seja dos Abexims, ou seja nossa, posto que em differentes estilos, os quays era necessario reduzir a

40 B. Teles: Historia Geral de Ethiopia... Carta laudatoria de Francisco Manuel de Melo ( $\left.f^{\circ} \mathrm{XI}\right)$. Sobre su autor, cf. Ios recientes estudios de A. Bernat Vistarini: Francisco Manuel de Melo (1608-1666): textos y contextos del barroco peninsular, Palma de Mallorca, 1992; y P. Serra: Conversas civis: estudos sobre D. Francisco Manuel de Melo, Salamanca, 2003; asi como la ed. de J. Estruch Tobella a su Historia de los movimientos, separación y guerra de Cataluña, Madrid, 1996.

41 B. Teles: Historia Geral de Ethiopia... Las citas que siguen proceden de la "Carta del patriarca de Ctiopia para el Padre Balthezar Telies". Firmada por "Affonso Mendes». Fechada en Goa, 29 de setiembre de 1655 . 
concordia, por o Padre Pero Pays escrever en Portuguez, sendo Castelhano de naçam, e que entrou en Portugal jà muyto homem, depoys de ter acabada sua Theologia e ser Sacerdote. E a os tays sempre custuma ser muy difficultosa a lingoa Portogueza, e o sonsonete d'ella. E ainda que elle era de Patria Toledano e nobre per geraçam e por isso muy apurado entre os cortesãos Castelhanos, entre nós era havido por enxacoco..." Es decir, los portugueses no lo consideraban de los suyos, sino un extranjero que hablaba con acento extraño, como se desprende de la inmediata cita clásica aludiendo a la desfavorable consideración del estilo de Tito $\mathrm{Li}$ vio entre los romanos a causa de su origen paduano, a su famosa patavinitas.

Finalmente, si Manoel d'Almeyda sólo tenía que descalificar a Pedro Páez, el patriarca debe rechazar también a Manoel d' Almeyda, para lo cual nada mejor que equipararlo con el jesuita español y apoyarse en otro ejemplo clásico: «E o padre Manoel d'Almeyda com a lingoa Portugueza the ser materna, e a criançam muy polida, por ser natural da nobre cidade de Viseu, se atou tanto á disposiçam e palavras do Padre Pero Pays, que tambem Ihe bebeo em grande parte os vicios déllas, com Alexandre a manqueyra de Leonides seu ayo". Hay que conceder a Afonso Mendes que el padre Almeyda había hablado por boca del jesuita español, pero, en cualquier caso, toda la justificación desprende un inequívoco perfume de patriotismo portugués, por encima de la solidaridad siempre presente en la internacional jesuítica.

Recientemente Hervé Pennec ha vuelto a analizar minuciosamente los textos en cuestióri, con el propósito manifiesto de proceder a "deconstruir la imagen hagiográfica" de Pedro Páez, lo cual le deja a salvo de toda sospecha de inclinación a favor del misionero español. Sin embargo, el historiador francés ha encontrado signos inequívocos de una operación de censura de la obra de Pedro Páez por parte del patriarca Afonso Mendes, que posiblemente fue el responsable directo de la devolución del manuscrito a Etiopía rechazando su publicación. Más tarde, Manoel de Almeida sería el encargado de “reescribir y a veces 'refutar' la Historia de Páez» ${ }^{42}$. Si los motivos de esta censura y de esta refutación obedecen para el historiador francés solamente a las tensiones en el interior de la propia orden, Ivo Carneiro de Sousa, por su parte, ensancha el contexto de la publicación de la obra de Baltasar Teles en un sentido más próximo a nuestras presunciones: "Más allá del sistema narrativo que, subráyese, es naturalmente también un valor, se hace necesario refrendar los discursos en función de un sistema de valores dominante. Amplio y generoso. Reuniendo geografias, literaturas, ciencias y técnicas, naturalmente, pero configurado de modo esencial por objetivos religiosos o, si se quiere, por una recurrente reflexión sobre la misión especifica de Portugal en una historia salutis universal. Etiopia es un caso específico y fundamental de esta misión»43.

En definitiva, y para ir cerrando el caso, la reticencia para con la obra de Pedro Páez de sus sucesores portugueses en la misión de Etiopía se inscribe en el

42 H. Pennec: Des Jésuites..., especialmente, pp. 244-306.

${ }^{43}$ I. Carneiro de Sousa: A crónica..., pág. 138. 
contexto del nacionalismo jesuítico portugués de la época, como ha subrayado Dauril Alden, que ha señalado de modo general la hostilidad de la Compañía frente a la agregación de Portugal a los Austrias españoles y su apoyo a las alteraciones de Evora de 1637 y a la restauración bragancista de 1640, al tiempo que ha sacado a luz la queja formulada en 1584 por los jesuitas hispanos residentes en Portugal contra sus hermanos de orden, que «estaban buscando deliberadamente el modo de alejarlos de la provincia a causa de su origen nacional», así como la orden girada en 1589 ( $\mathrm{y}$ reiterada al año siguiente) por el general Acquaviva a un inspector provincial para que "por el bien de la religión y la paz del reino" castigase a aquellos jesuitas que en Portugal manifestasen sentimientos nacionalistas ${ }^{44}$.

La segunda misión de Etiopia, desde sus prometedores inicios y sus éxitos indudables hasta su fracaso final, había coincidido con el periodo de la unión de las coronas, de la "agregación» de Portugal a la Monarquía Hispánica. Este hecho había marcado la evolución de la acción de los jesuitas en Abisinia, del mismo modo que había repercutido en otros lugares del Imperio portugués de Asia. En efecto, la misión se había visto influenciada por varios hechos conectados: su desarrollo en un área de dominio portugués pero bajo un monarca castellano, su realización a cargo de los religiosos de una orden de reclutamiento internacional en la que convivian españoles y portugueses y, finalmente, su encuadre en un momento de rivalidad entre diversas órdenes en relación con las áreas reservadas para su labor evangelizadora en los territorios ultramarinos situados respectivamente bajo las esferas de influencia de España y Portugal. Todas estas circunstancias pudieron lesionar la objetividad a la hora de ponderar los aciertos y los errores, los éxitos y los fracasos de la actividad misionera. Sin embargo, el tiempo ha decantado el juicio sobre hechos y personas.

En concreto, en el caso que aqui nos interesa, se ha llegado a una rara unanimidad en la valoración de la figura y la obra de Pedro Páez. Así, E. A. W. Budge, en su clásica History of Ethiopia, podia asentar con sobriedad este futurible: "Si Páez hubiese vivido algunos años más, la historia de Abisinia entre 1623 y 1632 habría sido diferente" 45 . Por su parte, Alberto Feio puede afirmar, en su introducción a su edición de la História da Etiópia: «Bajo todos los puntos de vista, el más grande de los misioneros de Etiopía fue el padre Pedro Páez"; para proseguir más tarde: «Páez es para Etiopía lo que Francisco Xavier para la India» ${ }^{46}$. $Y$, finalmente, en la misma línea, Philip Caraman puede concluir: "Su éxito misional iguala al menos, si es que no lo supera, al de su predecesor Matteo Ricci en China" ${ }^{47}$. No parece, pues, ningún ejercicio de hagiografía afirmar que Francisco Xavier en la India, Matteo Ricci en China y Pedro Páez en Etiopía fueron las tres grandes figuras de la evangelización en Oriente en esta época de grandes esperanzas.

44 D. Alden: The Making..., pp. 91-100.

${ }^{45}$ E. A. W. Budge: History of Ethiopia: Nubia and Abyssinia, Londres, 1928, pp. 389-390. (Apud P Caraman: L'empire perdu..., pág. 218).

46 Pero Pais: História da Etiópia... (A. Feio: Notícia bio-bibliográfica, pág. XXXI y pág. XXXIV).

${ }^{47}$ P. Caraman: L'empire perdu..., pág. 12. 